OPEN ACCESS

Edited by:

Ana lgea,

Biomedical Research Center,

University of Vigo, Spain

Reviewed by:

Rana Gupta,

University of Texas Southwestern Medical Center, United States

Mikhail Kolonin

The University of Texas Health

Science Center at Houston,

United States

*Correspondence:

Antonios Chatzigeorgiou achatzig@med.uoa.gr

Specialty section:

This article was submitted to

Molecular Medicine,

a section of the journal

Frontiers in Cell and Developmental

Biology

Received: 05 May 2020

Accepted: 26 June 2020

Published: 14 July 2020

Citation:

Pyrina I, Chung K-J,

Michailidou Z, Koutsilieris $M$,

Chavakis T and Chatzigeorgiou A

(2020) Fate of Adipose Progenitor

Cells in Obesity-Related Chronic

Inflammation.

Front. Cell Dev. Biol. 8:644.

doi: 10.3389/fcell.2020.00644

\section{Fate of Adipose Progenitor Cells in Obesity-Related Chronic Inflammation}

\author{
Iryna Pyrina ${ }^{1}$, Kyoung-Jin Chung ${ }^{1}$, Zoi Michailidou ${ }^{2}$, Michael Koutsilieris $^{3}$, \\ Triantafyllos Chavakis ${ }^{1,2,4}$ and Antonios Chatzigeorgiou ${ }^{1,3 *}$
}

${ }^{1}$ Institute for Clinical Chemistry and Laboratory Medicine, University Hospital and Faculty of Medicine Technische Universität Dresden, Dresden, Germany, ${ }^{2}$ Centre for Cardiovascular Science, Queen's Medical Research Institute, University of Edinburgh, Edinburgh, United Kingdom, ${ }^{3}$ Department of Physiology, Medical School, National and Kapodistrian University of Athens, Athens, Greece, ${ }^{4}$ Paul Langerhans Institute Dresden of the Helmholtz Center Munich, University Hospital and Faculty of Medicine, Technische Universität Dresden, Dresden, Germany

Adipose progenitor cells, or preadipocytes, constitute a small population of immature cells within the adipose tissue. They are a heterogeneous group of cells, in which different subtypes have a varying degree of commitment toward diverse cell fates, contributing to white and beige adipogenesis, fibrosis or maintenance of an immature cell phenotype with proliferation capacity. Mature adipocytes as well as cells of the immune system residing in the adipose tissue can modulate the function and differentiation potential of preadipocytes in a contact- and/or paracrine-dependent manner. In the course of obesity, the accumulation of immune cells within the adipose tissue contributes to the development of a pro-inflammatory microenvironment in the tissue. Under such circumstances, the crosstalk between preadipocytes and immune or parenchymal cells of the adipose tissue may critically regulate the differentiation of preadipocytes into white adipocytes, beige adipocytes, or myofibroblasts, thereby influencing adipose tissue expansion and adipose tissue dysfunction, including downregulation of beige adipogenesis and development of fibrosis. The present review will outline the current knowledge about factors shaping cell fate decisions of adipose progenitor cells in the context of obesity-related inflammation.

Keywords: preadipocyte, adipose progenitor, inflammation, adipogenesis, beiging, obesity, fibrosis

\section{INTRODUCTION}

In the past two decades, adipose tissue (AT) has been extensively studied in both rodents and humans, especially regarding mechanisms involved in obesity-related metabolic dysregulation. There are two morphologically and functionally distinct types of AT: white AT (WAT) and brown AT (BAT). WAT is predominantly responsible for energy storage in the form of triglycerides and secretes hormonal regulators, namely adipokines, such as leptin and adiponectin, which can regulate whole-body's metabolic homeostasis. BAT, in contrast, has a non-shivering heat production capacity, due to expression of uncoupling protein-1 (UCP-1) (Kershaw and Flier, 2004; Peirce et al., 2014; Rosen and Spiegelman, 2014). Beige, or brite adipocytes represent a type of adipocytes that morphologically resemble white rather than brown fat cells and reside within WAT, but express 
UCP-1 and exert brown-like properties (Rosen and Spiegelman, 2014; Alexaki and Chavakis, 2016; Cinti and Giordano, 2020).

In addition to adipocytes, the stromal vascular cell fraction (SVF) of the AT contains further cell types, such as endothelial cells, various immune cells and adipocyte progenitors (preadipocytes or adipose progenitors cells, APs) (Ailhaud et al., 1992; Church et al., 2014). APs reside in perivascular regions of the AT, and can differentiate into mature adipocytes (Tang et al., 2008; Rosen and Spiegelman, 2014; Vishvanath et al., 2016). A recent study defined a developmental hierarchy of APs starting from Dipeptidyl peptidase-4-postive $\left(\mathrm{DPP} 4^{+}\right)$cells that give rise to committed ICAM1 ${ }^{+}$and $\mathrm{CD}_{142^{+}}$preadipocytes capable of adipogenic differentiation (Merrick et al., 2019). Commonly, preadipocytes are described as $\mathrm{CD} 45^{-}, \mathrm{CD} 31^{-}, \mathrm{Lin}^{-}, \mathrm{CD} 29^{+}$, and Sca- $1^{+}$cells (Rodeheffer et al., 2008; Tang et al., 2008; Berry and Rodeheffer, 2013). Platelet-derived growth factor-receptor $\beta$ positive (PDGFR $\beta^{+}$) APs were described as predisposed to a white adipogenic (Gao et al., 2018), while PDGFR $\alpha^{+}$progenitors to a beige adipogenic or a fibrogenic phenotype (Lee et al., 2012; Marcelin et al., 2017). A recent study provides an insight in the heterogeneity of APs in the mouse VAT based on scRNAseq analysis, demonstrating the existence of two distinct populations of AT-derived stem cells and three populations of preadipocytes (Cho et al., 2019).

During obesity, the expansion of the AT is driven by two processes: hypertrophy (increased adipocyte size) and hyperplasia (increased adipocyte numbers). Hyperplastic growth is considered more metabolically favorable (Shao et al., 2018; Vishvanath and Gupta, 2019), while AT hypertrophy is associated with the development of hypoxia and release of pro-inflammatory cytokines and chemokines by the adipocytes, leading to the recruitment of immune cells and the formation of a pro-inflammatory microenvironment in the AT (Arner et al., 2010; Chatzigeorgiou et al., 2014; García-Martín et al., 2015; Choe et al., 2016; Chung et al., 2018; Michailidou, 2019). Macrophages play a crucial role in the development of AT inflammation. They shift from an anti-inflammatory M2-like $(\mathrm{M} 2-\mathrm{M} \Phi)$ to a pro-inflammatory M1-like (M1-M $\Phi)$ phenotype and form "crown-like" structures surrounding dead adipocytes (Cinti et al., 2005; Lumeng et al., 2007a; Chawla et al., 2011; Cinti and Giordano, 2020). M1-MФ secrete pro-inflammatory mediators such as tumor necrosis factor (TNF), interleukin 1 beta (IL-1 $\beta$ ), and IL-6 (Chawla et al., 2011; Chmelar et al., 2013; Shapouri-Moghaddam et al., 2018). AT inflammation is also featured by the accumulation within the obese AT of several innate and adaptive immune cells including natural killer cells, neutrophils, $\mathrm{CD}^{+}$cytotoxic- and type $1 \mathrm{~T}$ helper-lymphocytes, which also produce pro-inflammatory factors (Cildir et al., 2013; Chung et al., 2018; Kane and Lynch, 2019).

Studies suggest that various stromal cells, including AT fibroblasts and endothelial cells, create an adipose niche for APs (Jiang et al., 2017; Zhang et al., 2018), while resident and infiltrating immune cells also contribute to the niche formation, especially in the context of obesity-related inflammation (Nawaz et al., 2017). Considering that preadipocytes are plastic cells that respond to both niche and systemic signals (Jeffery et al., 2016), the pro-inflammatory microenvironment of the obese AT might play a critical role in determining the fate of APs. The present review focuses on the current knowledge about AP fate driven by both intracellular and extracellular factors in the context of obesity-related chronic inflammation.

\section{ADIPOGENESIS}

\section{White Adipogenesis and AT Expansion}

The hyperplastic growth of the AT occurs through the process of adipogenesis, namely the highly dynamic transformation of immature fibroblast-like precursor cells into mature lipidloaded adipocytes (Rosen and MacDougald, 2006). Peroxisome proliferator-activated receptor- $\gamma(\operatorname{PPAR} \gamma)$ and members of the CCAAT-enhancer-binding proteins (C/EBP) family are masterregulators of this process. However, a considerable number of signaling pathways, including Wnt, Notch, Hedgehog, MAPK, and pro- and anti-adipogenic mediators (KLF and GATA transcription factors, cell cycle proteins) regulate the adipogenic conversion (Farmer, 2006; Rosen and MacDougald, 2006; Ghaben and Scherer, 2019). Of note, APs from different AT depots display qualitative and quantitative heterogeneity. For instance, in both mice and humans, APs from subcutaneous fat depots have shown in vitro higher growth rates and adipogenic potential compared to those from visceral AT (Permana et al., 2004; Tchkonia et al., 2005; Macotela et al., 2012). Nevertheless, in vivo evidence from adult C57BL/6 mice, supports that following HFD-feeding, visceral AT expands through both adipocyte hypertrophy and hyperplasia, while subcutaneous AT almost exclusively via cellular hypertrophy (Vishvanath and Gupta, 2019). Several markers, such as CD36 and Zfp423 have been suggested to define preadipocyte populations with pronounced adipogenic capacity (Gupta et al., 2012; Gao et al., 2017).

A crosstalk between APs and immune cells could orchestrate adipogenesis in both lean and obese state (Bing, 2015; Chung et al., 2017). For instance, macrophages constitute $5-10 \%$ of the SVF in lean mice and their numbers increase in obesity (Weisberg et al., 2003; Weinstock et al., 2019; Daemen and Schilling, 2020). Both proliferation of tissue-resident macrophages and monocyte infiltration contribute to the expansion of this population in the obese AT (Weisberg et al., 2003; Amano et al., 2014; Zheng et al., 2016). Several studies have shown that pro-inflammatory macrophage-conditioned medium inhibits AP differentiation and leads to insulin resistance in mouse and human preadipocytes in vitro (Constant et al., 2006; Lacasa et al., 2007; Lumeng et al., 2007b). The potential contribution of individual components of the macrophage secretome to this process has gained strong attention. TNF is a major factor contributing to the anti-adipogenic effect of macrophages, possibly via an epigenetic reprogrammingdependent mechanism (Isakson et al., 2009; Andersen et al., 2019). IL-6 exerts an inhibitory effect on IRS-1, Glut4, and $\operatorname{PPAR} \gamma$, thereby contributing to the decreased adipogenic capacity of human preadipocytes (Rotter et al., 2003; Gustafson and Smith, 2006; Almuraikhy et al., 2016). IL-1 $\beta$ from proinflammatory macrophages inhibits insulin sensitivity in both 
APs and mature adipocytes of mice and humans (Lagathu et al., 2006; Gao et al., 2014). Moreover, the aforementioned cytokines participate in a positive-feedback loop induction of pro-inflammatory gene expression (IL-6, MCP-1, IL-1 $\beta$, TNF, and IL-8) in APs (Gustafson and Smith, 2006; Isakson et al., 2009; Gao et al., 2014). Priming of human preadipocytes toward a pro-inflammatory phenotype is also mediated by elevated extracellular glucose levels, which accompany obesity and insulin resistance (Rønningen et al., 2015). Pro-inflammatory priming of murine preadipocytes is also mediated by leptin, the levels of which are elevated during obesity (Ouchi et al., 2011; Palhinha et al., 2019). Contrastingly, adiponectin, which is decreased in the obese AT, promotes the differentiation of 3T3-L1 preadipocytes and insulin sensitivity (Fu et al., 2005).

Besides macrophages that contribute to obese AT remodeling, other immune cells within the AT can affect preadipocyte differentiation as well. For instance, murine monocyte-derived dendritic cells (DCs), which accumulate in the obese AT, display anti-adipogenic properties in vitro (Pamir et al., 2015; Macdougall and Longhi, 2019). The inhibition of AP differentiation during obesity and AT inflammation promotes the hypertrophic, rather than hyperplastic expansion of the AT, due to storage of the supplied energy in the form of lipids by mature adipocytes and not by differentiating APs (Hammarstedt et al., 2018; Gustafson et al., 2019).

Apart from immune cells, the interaction of APs with the highly abundant endothelial cells of the AT may shape the adipogenic potential of preadipocytes, likely via vasculaturederived factors (Cao, 2007). Indeed, vascular endothelial growth factor (VEGF) is considered a key factor coupling adipo- and angiogenesis in the mouse AT and may favor adipogenesis within adipogenic/angiogenic cell clusters (Nishimura et al., 2007; Sun et al., 2012; Breier et al., 2017). Along this line, a recent study suggested a possible role of endothelial cells in the regulation of fatty acid transport and PPAR $\gamma$ activation in human preadipocytes, due to secretion of PPAR $\gamma$ ligands by endothelial cells (Gogg et al., 2019). Moreover, a spatial and functional overlap of $\mathrm{CD} 34^{+}$APs with pericytes has been described, which plays a role in the stabilization of the AT vasculature (Traktuev et al., 2008).

Of interest, a subpopulation of $\mathrm{CD}_{142}{ }^{+}$adipogenesisregulatory cells (Aregs) was recently identified among the stromal cell population of the mouse AT. This unique subtype of precursor cells is increased in the obese AT and can suppress the differentiation of preadipocytes in a paracrine-dependent manner (Schwalie et al., 2018). However, as described above, a later study did not support this finding (Merrick et al., 2019).

\section{Beige Adipogenesis}

Beige adipogenesis is integral to the metabolic homeostasis of WAT. It contributes to insulin sensitivity by upregulating molecular thermogenic signatures of WAT. Specifically, upon adrenergic stimulation or exposure to cold, beige or brite adipocytes can upregulate UCP-1 expression and adopt a thermogenic phenotype, resembling brown adipocytes (Wu et al., 2012; Alexaki and Chavakis, 2016; Wang and Seale, 2016; Shao et al., 2019). However, a non-canonical UCP-1 mechanism can also contribute to the formation of this phenotype (Bertholet et al., 2017; Ikeda et al., 2018). Lineage-tracing studies allowed to distinguish between $\mathrm{Myf5}{ }^{+}$progenitors that can differentiate into brown adipocytes or myocytes, and $\mathrm{Myf5}^{-}$precursors that are committed to white and beige adipocyte differentiation (Gesta et al., 2007; Obregon, 2014; Peirce et al., 2014). Furthermore, apart from the common white-beige progenitor, beige adipocytes can also derive from a transdifferentiation of mature white adipocytes into beige ones (Lee et al., 2012; Rosenwald et al., 2013).

Until now, "beiging" or "browning" of the WAT is considered as metabolically more favorable than "whitening," and is essentially a feature of the lean WAT, while it is diminished in the course of obesity and the development of AT inflammation (Alexaki and Chavakis, 2016). Indeed, several innate and adaptive immune cell types have been implicated in the regulation of beige adipogenesis in a positive or negative fashion (Lee et al., 2015; Chung et al., 2017). Multiple studies have suggested the beneficial role of cells of type 2 immunity, such as eosinophils and M2$M \Phi$ in the induction and maintenance of beige adipogenesis in mice, especially in the lean WAT (Lee et al., 2013; Qiu et al., 2014; Alexaki and Chavakis, 2016). For instance, the release of IL- 4 by eosinophils is required for the maintenance of the alternatively activated $\mathrm{M} 2-\mathrm{M} \Phi$ population, which promote induction of beige adipogenesis in mice (Wu et al., 2011; Qiu et al., 2014; Hui et al., 2015). Nevertheless, contradictory data exist pertinent to the mechanism by which $\mathrm{M} 2-\mathrm{M} \Phi$ exert their beige adipogenesis-promoting effect on APs and mature adipocytes and whether the latter may depend on the release of catecholamines by the M2-MФ or not (Qiu et al., 2014; Fischer et al., 2017). In addition, type 2 innate lymphoid cells (ILC2) promote beige adipogenesis in mice, predominantly by propagating the maintenance of eosinophils and $\mathrm{M} 2-\mathrm{M} \Phi$ in a IL-5- and IL-13-related manner (Molofsky et al., 2013). Along this line, type 2 cytokines secreted by ILC2s and eosinophils can stimulate beige adipogenesis in murine PDGFR $\alpha^{+}$APs, thereby triggering signaling via the IL- $4 \mathrm{R} \alpha$ present on the latter (Lee et al., 2015). Another mechanism suggests that mouse AT beiging is stimulated by IL-33-mediated activation of ILC2 and the release by them of a methionine-enkephalin peptide (Brestoff et al., 2014). Interestingly, a recent study showed that murine PRDM16-expressing adipocytes, favor a fibrogenic-toadipogenic transition of APs, thus promoting beige adipogenesis by secreting $\beta$-hydroxybutyrate (Wang W. et al., 2019).

In contrast, the development of a pro-inflammatory microenvironment in the obese WAT restricts the potential of APs toward beige adipogenesis. The increased numbers of M1-MФ and the concomitant release of pro-inflammatory mediators, such as IL-1 $\beta$ and TNF, contribute to the impaired browning of the obese murine WAT and the suppression of UCP-1 expression, likely in a Toll-like receptor 4 (TLR4) and Nod-like receptor 3 (NLRP3) inflammasome-dependent way (Sakamoto et al., 2016; Okla et al., 2018). Additionally, signaling via the IL-18/IL-18R1 system has been reported to impede energy expenditure and mouse AT beiging in vivo (Pazos et al., 2015). Interestingly, a major mechanism involved in the diminished beige adipogenesis in mice and humans during obesity-related 


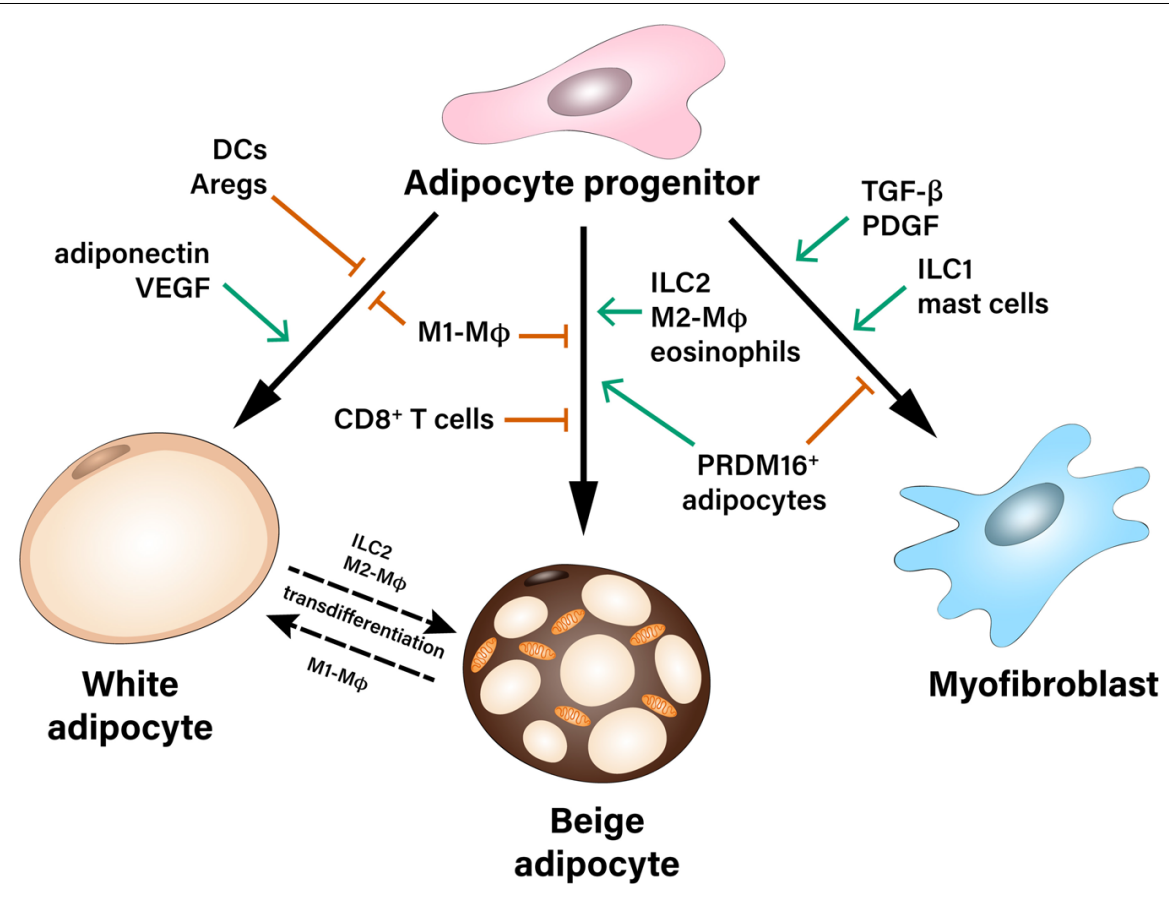

FIGURE 1 | Multiple contact- and paracrine-mediated interactions shape differentiation of adipocyte progenitors toward white or beige adipocytes or myofibroblasts. Pro-inflammatory M1-like macrophages (M1-M $\Phi$ ) inhibit both white and beige differentiation of preadipocytes. Dendritic cells (DCs), as well as adipogenesis-regulatory cells (Aregs) contribute to the inhibition of white adipogenic differentiation. On the other hand, paracrine factors like adiponectin and VEGF stimulate precursor's commitment toward white fat cells. Beige adipocytes can derive either from common white/beige adipocyte progenitors or from transdifferentiation of mature white adipocytes. Pro-inflammatory M1-M $\Phi$ and CD8 ${ }^{+} \mathrm{T}$ cells inhibit beige adipogenesis during obesity, while Type 2 innate lymphoid cells (ILC2), M2-like macrophages (M2-MФ), eosinophils as well as a subpopulation of PRDM16+ adipocytes were described as positive regulators of beige adipogenesis. Adipocyte progenitors can differentiate into myofibroblasts and therefore, contribute to the development of fibrosis. This process is stimulated by pro-fibrotic factors (TGF- $\beta$, PDGF) as well as type 1 innate lymphoid cells (ILC1) and mast cells.

WAT inflammation relies on the direct integrin-mediated interaction between M1-like macrophages and APs as well as mature adipocytes (Chung et al., 2017). Furthermore, CD8 ${ }^{+}$ $\mathrm{T}$ cells were also shown to inhibit beiging of the obese murine WAT in an IFN- $\gamma$-dependent manner (Moysidou et al., 2018).

\section{FIBROSIS}

Fibrosis is considered a pathophysiological consequence of the persistent low-grade inflammation in the WAT in obesity. Myofibroblasts are the major cell type contributing to the extracellular matrix (ECM) deposition in fibrosis of various organs. They can originate from different precursor cells under the effect of transforming growth factor beta 1 (TGF- $\beta 1$ ) and platelet-derived growth factor (PDGF) deriving from inflammatory cells (Wynn, 2008; Sun et al., 2013; Marcelin et al., 2019).

TGF- $\beta$ inhibits human preadipocyte differentiation into mature adipocytes, while it promotes collagen production and cell proliferation, a process that can be controlled by JakStat signaling (Weiner et al., 1989; Keophiphath et al., 2009; Babaei et al., 2018). TGF- $\beta$ is involved in the generation of Sca- $1^{-} \mathrm{SMA}^{+}$ITGA $^{+}$fibrogenic progenitor cells in the murine WAT. This process depends on myocardin-related transcription factor A (MRTFA) and results in the shift of the fate of perivascular progenitors from APs with adipogenic potential toward pro-fibrotic cells (Lin et al., 2018).

PDGFR $\alpha$ has been recognized as an anti-adipogenic factor that favors the generation of profibrotic cells in mice (Iwayama et al., 2015; Sun et al., 2017). Marcelin et al. showed the existence of two subsets of PDGFR $\alpha^{+}$adipocyte progenitors based on the level of their CD9 expression. In both humans and mice, AT CD9high cells were described as pro-fibrotic progenitors, while CD9 ${ }^{\text {low }}$ precursors were rather committed to adipogenesis. The CD9 ${ }^{\text {low }}$ subpopulation was almost lost in the fibrotic obese WAT, while CD9high progenitors' frequency positively correlated with the degree of WAT fibrosis (Marcelin et al., 2017). Similar characterizations of profibrotic vs. adipogenic cells were identified in humans and mice based on Ly6C and CD34 expression. Specifically, Hepler et al. (2018) described in the mouse AT the coexistence of $\mathrm{Ly}_{6 \mathrm{C}}+\mathrm{PDGFR}^{+}$fibroinflammatory progenitors along with the highly adipogenic Ly6C $^{-}$CD9 $^{-}$PDGFR $^{+}$cells. Similarly, CD $34^{\text {high }}$ APs were described as pro-fibrotic cells in the human visceral AT according to their secretome profile (Buffolo et al., 2019). On the contrary, another study did not find significant differences in proliferative, adipogenic and fibrogenic potential between CD34- ${ }^{-}, \mathrm{CD}_{4}{ }^{\text {low }}$, and CD34 ${ }^{\text {high }}$ cells (Raajendiran et al., 2019). Subpopulations of fibro-inflammatory progenitors increase in 
numbers following AT expansion, and exert an anti-adipogenic effect on other adipocyte precursor cells via secretion of soluble factors (Marcelin et al., 2017; Hepler et al., 2018; Buffolo et al., 2019).

Importantly, the extent of AT fibrosis positively correlates with the number of crown-like structures in the obese AT (Cinti et al., 2005; Buechler et al., 2015), implying that AT fibrosis may be triggered by the pro-inflammatory microenvironment. Transcriptomic analysis of human preadipocytes cultured with conditioned medium from pro-inflammatory macrophages revealed an upregulation in the expression of ECM components (Henegar et al., 2008). Moreover, macrophage-derived IL-1 $\beta$ promotes the expression of ECM remodeling enzymes, such as metalloproteinases 1 (MMP1) and 3 (MMP3), in human APs (Gao and Bing, 2011). Not only cells of the monocytic lineage contribute to the stimulation of ECM production by preadipocytes. Mast cells accumulate in the mouse and human obese AT preferentially in depots with progressed fibrosis and provoke the secretion of collagen $\mathrm{V}$ by AT fibroblasts, which can contribute to the suppression of the adipogenic differentiation of APs. Of note, the secretion of collagen $\mathrm{V}$ in the obese AT is triggered by the release of mast cell protease 6 (MCP-6) by mature mast cells (Divoux et al., 2012; Hirai et al., 2014). Other ECM components of the AT, like collagen VI and its derivative endotrophin, can trigger fibrosis in the AT and contribute to preadipocytes' myofibroblastic transformation (Khan et al., 2009; Sun et al., 2014; Jones et al., 2020). Additionally, while ILC2 drive beige adipogenesis, type 1 innate lymphoid cells (ILC1) promote AT fibrogenesis in human and mice in an IFN- $\gamma$ dependent manner (Wang H. et al., 2019).

In conclusion, in the lean WAT, APs represent a highly heterogeneous cell population; yet with intrinsic white or beige differentiation potential rather than a pro-fibrotic one. Contrastingly, in obesity, interactions of APs with cells of both the innate and adaptive immunity that accumulate in the obese WAT can trigger fibrosis by inducing a pro-fibrotic transcriptional program in APs.

\section{CONCLUSION AND FUTURE PERSPECTIVE}

APs are a highly heterogeneous population of stromal AT cells. Different subtypes of APs can have a varying degree of commitment toward white, beige adipocyte or fibroblast

\section{REFERENCES}

Ailhaud, G., Grimaldi, P., and Négrel, R. (1992). Cellular and molecular aspects of adipose tissue development. Annu. Rev. Nutr. 12, 207-233. doi: 10.1146/ annurev.nu.12.070192.001231

Alexaki, V. I., and Chavakis, T. (2016). The role of innate immunity in the regulation of brown and beige adipogenesis. Rev. Endocr. Metab. Disord. 17, 41-49. doi: 10.1007/s11154-016-9342-7

Almuraikhy, S., Kafienah, W., Bashah, M., Diboun, I., Jaganjac, M., Al-Khelaifi, F., et al. (2016). Interleukin-6 induces impairment in human subcutaneous differentiation. Along this line, extensive in vivo and in vitro studies report the identification of numerous AP subpopulations. However, in several of these studies the characterization of the multiple AP subtypes is based on different experimental approaches (Burl et al., 2018; Cho et al., 2019; Min et al., 2019). This issue is further complicated by the regional variation of APs within the different fat depots and the distinct abundance of different progenitor subtypes therein. Thus, the identification of reliable and broadly acceptable molecular and surface markers to distinguish the various AP subtypes is imperative. It is recognized, that the number of adipocytes is set during childhood and adolescence and stays nearly constant in adulthood with a $10 \%$ turnover rate in lean and obese individuals (Spalding et al., 2008; Rodríguez et al., 2015; Meln et al., 2019). Consequently, a deeper insight into AP subtypes and crosstalk mechanisms with other cells could shed the light on how the fate of preadipocytes can be predetermined early in life and lead to the development of obesity and accompanying metabolic complications later.

Importantly, the crosstalk between APs and immune cells in the AT orchestrates AP fate in both lean and obese state. For instance, obesity-related AT inflammation leads to reduced beige adipogenic and increased pro-fibrotic potential of APs. So far, the majority of studies have focused on the interaction between macrophages and APs, while less information exists pertinent to the role of cells of the adaptive immunity as well as less abundant stromal cell types, which may also shape the differentiation potential of APs (Figure 1). Identification of the specific contribution of different immune and stromal cell populations, which may affect fate decisions of APs, as well as better understanding of the molecular mechanisms implicated in this crosstalk is needed for the development of new therapeutic strategies against obesity-related AT dysfunction.

\section{AUTHOR CONTRIBUTIONS}

IP, TC, and AC wrote the manuscript, while ZM, K-JC, and MK edited the manuscript. All authors contributed to the article and approved the submitted version.

\section{FUNDING}

This work was supported by the German Research Foundation (Deutsche Forschungsgemeinschaft, Grant No. 1862/3-1 to AC and Grant Nos. IRTG2251 and SFB-TR 127 to TC). adipogenesis in obesity-associated insulin resistance. Diabetologia 59, 24062416. doi: 10.1007/s00125-016-4031-3

Amano, S. U., Cohen, J. L., Vangala, P., Tencerova, M., Nicoloro, S. M., Yawe, J. C., et al. (2014). Local proliferation of macrophages contributes to obesityassociated adipose tissue inflammation. Cell Metab. 19, 162-171. doi: 10.1016/j. cmet.2013.11.017

Andersen, E., Ingerslev, L. R., Fabre, O., Donkin, I., Altıntaş, A., Versteyhe, S., et al. (2019). preadipocytes from obese humans with type 2 diabetes are epigenetically reprogrammed at genes controlling adipose tissue function. Int. J. Obes. 43, 306-318. doi: 10.1038/s41366-018-0031-3 
Arner, E., Westermark, P. O., Spalding, K. L., Britton, T., Rydén, M., Frisén, J., et al. (2010). Adipocyte turnover: relevance to human adipose tissue morphology. Diabetes 59, 105-109. doi: 10.2337/db09-0942

Babaei, R., Schuster, M., Meln, I., Lerch, S., Ghandour, R. A., Pisani, D. F., et al. (2018). Jak-TGF $\beta$ cross-talk links transient adipose tissue inflammation to beige adipogenesis. Sci. Signal. 11:eaai7838. doi: 10.1126/scisignal.aai7838

Berry, R., and Rodeheffer, M. S. (2013). Characterization of the adipocyte cellular lineage in vivo. Nat. Cell Biol. 15, 302-308. doi: 10.1038/ncb2696

Bertholet, A. M., Kazak, L., Chouchani, E. T., Bogaczyńska, M. G., Paranjpe, I., Wainwright, G. L., et al. (2017). Mitochondrail patch clamp of beige adipocytes reveals UCP1-positive and UCP1-negative cells both exhibiting futile creatine cycling. Cell Metab. 25, 811.e4-822.e4. doi: 10.1016/j.cmet.2017.03.002

Bing, C. (2015). Is interleukin- $1 \beta$ a culprit in macrophage-adipocyte crosstalk in obesity? Adipocyte 4, 149-152. doi: 10.4161/21623945.2014.979661

Breier, G., Chavakis, T., and Hirsch, E. (2017). Angiogenesis in metabolic-vascular disease. Thromb. Haemost. 117, 1289-1295. doi: 10.1160/TH17-05-0325

Brestoff, J. R., Kim, B. S., Saenz, S. A., Stine, R. R., Monticelli, L. A., Sonnenberg, G. F., et al. (2014). Group 2 innate lymphoid cells promote beiging of white adipose tissue and limit obesity. Nature 519, 242-246. doi: 10.1038/nature14115

Buechler, C., Krautbauer, S., and Eisinger, K. (2015). Adipose tissue fibrosis. World J. Diabetes 6, 548-553. doi: 10.4239/wjd.v6.i4.548

Buffolo, M., Pires, K. M., Ferhat, M., Ilkun, O., Makaju, A., Achenbach, A., et al. (2019). Identification of a paracrine signaling mechanism linking CD34high progenitors to the regulation of visceral fat expansion and remodeling. Cell Rep. 29, 270.e5-282.e5. doi: 10.1016/j.celrep.2019.08.092

Burl, R. B., Ramseyer, V. D., Rondini, E. A., Pique-Regi, R., Lee, Y. H., and Granneman, J. G. (2018). Deconstructing adipogenesis induced by $\beta 3$ adrenergic receptor activation with single-cell expression profiling. Cell Metab. 28, 300.e4-309.e4. doi: 10.1016/j.cmet.2018.05.025

Cao, Y. (2007). Angiogenesis modulates adipogenesis and obesity. J. Clin. Invest. 117, 2362-2368. doi: 10.1172/JCI32239

Chatzigeorgiou, A., Kandaraki, E., Papavassiliou, A. G., and Koutsilieris, M. (2014). Peripheral targets in obesity treatment: a comprehensive update. Obes Rev. 15, 487-503. doi: 10.1111/obr.12163

Chawla, A., Nguyen, K. D., and Goh, Y. P. (2011). Macrophage-mediated inflammation in metabolic disease. Nat. Rev. Immunol. 11, 738-749. doi: 10. 1038/nri3071

Chmelar, J., Chung, K. J., and Chavakis, T. (2013). The role of innate immune cells in obese adipose tissue inflammation and development of insulin resistance. Thromb. Haemost. 109, 399-406. doi: 10.1160/TH12-09-0703

Cho, D. S., Lee, B., and Doles, J. D. (2019). Refining the adipose progenitor cell landscape in healthy and obese visceral adipose tissue using single-cell gene expression profiling. Life Sci. Alliance 2:e201900561. doi: 10.26508/lsa. 201900561

Choe, S. S., Huh, J. Y., Hwang, I. J., Kim, J. I., and Kim, J. B. (2016). Adipose tissue remodeling: its role in energy metabolism and metabolic disorders. Front. Endocrinol. 7:30. doi: 10.3389/fendo.2016.00030

Chung, K. J., Chatzigeorgiou, A., Economopoulou, M., Garcia-Martin, R., Alexaki, V. I., Mitroulis, I., et al. (2017). A self-sustained loop of inflammation-driven inhibition of beige adipogenesis in obesity. Nat. Immunol. 18, 654-664. doi: 10.1038/ni.3728

Chung, K. J., Nati, M., Chavakis, T., and Chatzigeorgiou, A. (2018). Innate immune cells in the adipose tissue. Rev. Endocr. Metab. Disord. 19, 283-292. doi: 10. 1007/s11154-018-9451-6

Church, C. D., Berry, R., and Rodeheffer, M. S. (2014). Isolation and study of adipocyte precursors. Methods Enzymol. 537, 31-46. doi: 10.1016/B978-0-12411619-1.00003-3

Cildir, G., Akincilar, S. C., and Tergaonkar, V. (2013). Chronic adipose tissue inflammation: all immune cells on the stage. Trends Mol. Med. 19, 487-500. doi: 10.1016/j.molmed.2013.05.001

Cinti, S., and Giordano, A. (2020). "The adipose organ," in The First Outstanding 50 Years of "Università Politecnica Delle Marche, eds S. Longhi, A. Monteriù, L. Aquilanti, M. G. Ceravolo, O. Carnevali, M. Giordano, et al. (Berlin: Springer), 167-183. doi: 10.1007/978-3-030-33832-9

Cinti, S., Mitchell, G., Barbatelli, G., Murano, I., Ceresi, E., Faloia, E., et al. (2005), Adipocyte death defines macrophage localization and function in adipose tissue of obese mice and humans. J. Lipid Res. 46, 2347-2355. doi: 10.1194/jlr. M500294-JLR200
Constant, V. A., Gagnon, A., Landry, A., and Sorisky, A. (2006). Macrophageconditioned medium inhibits the differentiation of 3T3-L1 and human abdominal preadipocytes. Diabetologia 49, 1402-1411. doi: 10.1007/s00125006-0253-0

Daemen, S., and Schilling, J. D. (2020). The interplay between tissue niche and macrophage cellular metabolism in obesity. Front. Immunol. 10:3133. doi: 10. 3389/fimmu.2019.03133

Divoux, A., Moutel, S., Poitou, C., Lacasa, D., Veyrie, N., Aissat, A., et al. (2012). Mast cells in human adipose tissue: link with morbid obesity, inflammatory status, and diabetes. J. Clin. Endocrinol. Metab. 97, 1677-1685. doi: 10.1210/ jc.2012-1532

Farmer, S. R. (2006). Transcriptional control of adipocyte formation. Cell Metab. 4, 263-273. doi: 10.1016/j.cmet.2006.07.001

Fischer, K., Ruiz, H. H., Jhun, K., Finan, B., Oberlin, D. J., van der Heide, V., et al. (2017). Alternatively activated macrophages do not synthesize catecholamines or contribute to adipose tissue adaptive thermogenesis. Nat. Med. 23, 623-630. doi: $10.1038 / \mathrm{nm} .4316$

Fu, Y., Luo, N., Klein, R. L., and Garvey, W. T. (2005). Adiponectin promotes adipocyte differentiation, insulin sensitivity, and lipid accumulation. J. Lipid Res. 46, 1369-1379. doi: 10.1194/jlr.M400373-JLR200

Gao, D., and Bing, C. (2011). Macrophage-induced expression and release of matrix metalloproteinase 1 and 3 by human preadipocytes is mediated by IL- $1 \beta$ via activation of MAPK signaling. J. Cell Physiol. 226, 2869-2880. doi: 10.1002/jcp. 22630

Gao, D., Madi, M., Ding, C., Fok, M., Steele, T., Ford, C., et al. (2014). Interleukin$1 \beta$ mediates macrophage-induced impairment of insulin signaling in human primary adipocytes. Am. J. Physiol. Endocrinol. Metab. 307, E289-E304. doi: 10.1152/ajpendo.00430.2013

Gao, H., Volat, F., Sandhow, L., Galitzky, J., Nguyen, T., Esteve, D., et al. (2017). CD36 is a marker of human adipocyte progenitors with pronounced adipogenic and triglyceride accumulation potential. Stem Cells 3, 1799-1814. doi: 10.1002/ stem. 2635

Gao, Z., Daquinag, A. C., Su, F., Snyder, B., and Kolonin, M. G. (2018). PDGFR $\alpha /$ PDGFR $\beta$ signaling balance modulates progenitor cell differentiation into white and beige adipocytes. Development 145, dev155861. doi: 10.1242/dev. 155861

García-Martín, R., Alexaki, V. I., Qin, N., Rubín de Celis, M. F., Economopoulou, M., Ziogas, A., et al. (2015). Adipocyte-specific hypoxia-inducible factor $2 \alpha$ deficiency exacerbates obesity-induced brown adipose tissue dysfunction and metabolic dysregulation. Mol. Cell Biol. 36, 376-393. doi: 10.1128/MCB.0043015

Gesta, S., Tseng, Y. H., and Kahn, C. R. (2007). Developmental origin of fat: tracking obesity to its source. Cell 131, 242-256. doi: 10.1016/j.cell.2007.10.004

Ghaben, A. L., and Scherer, P. E. (2019). Adipogenesis and metabolic health. Nat. Rew. Mol. Cell Biol. 20, 242-258. doi: 10.1038/s41580-018-0093-Z

Gogg, S., Nerstedt, A., Boren, J., and Smith, U. (2019). Human adipose tissue microvascular endothelial cells secrete PPAR $\gamma$ ligands and regulate adipose tissue lipid uptake. JCI Insight 4:e125914. doi: 10.1172/jci.insight.125914

Gupta, R. K., Mepani, R. J., Kleiner, S., Lo, J. C., Khandekar, M. J., Cohen, P., et al. (2012). Zfp423 expression identifies committed preadipocytes and localizes to adipose endothelial and perivascular cells. Cell Metab. 15, 230-239. doi: 10. 1016/j.cmet.2012.01.010

Gustafson, B., Nerstedt, A., and Smith, U. (2019). Reduced subcutaneous adipogenesis in human hypertrophic obesity is linked to senescent precursor cells. Nat. Commun. 10:2757. doi: 10.1038/s41467-019-10688-x

Gustafson, B., and Smith, U. (2006). Cytokines promote Wnt signaling and inflammation and impair the normal differentiation and lipid accumulation in 3T3-L1 preadipocytes. J. Biol. Chem. 281, 9507-9516. doi: 10.1074/jbc. M512077200

Hammarstedt, A., Gogg, S., Hedjazifar, S., Nerstedt, A., and Smith, U. (2018). Impaired adipogenesis and dysfunctional adipose tissue in human hypertrophic obesity. Physiol. Rev. 98, 1911-1941. doi: 10.1152/physrev.00034.2017

Henegar, C., Tordjman, J., Achard, V., Lacasa, D., Cremer, I., Guerre-Millo, M., et al. (2008). Adipose tissue transcriptomic signature highlights the pathological relevance of extracellular matrix in human obesity. Genome Biol. 9:R14. doi: 10.1186/gb-2008-9-1-r14

Hepler, C., Shan, B., Zhang, Q., Henry, G. H., Shao, M., Vishvanath, L., et al. (2018). Identification of functionally distinct fibro-inflammatory and 
adipogenic stromal subpopulations in visceral adipose tissue of adult mice. eLife 7:e39636. doi: 10.7554/eLife.39636

Hirai, S., Ohyane, C., Kim, Y. I., Lin, S., Goto, T., Takahashi, N., et al. (2014). Involvement of mast cells in adipose tissue fibrosis. Am. J. Physiol. Endocrinol. Metab. 306, 247-255. doi: 10.1152/ajpendo.00056.2013

Hui, X., Gu, P., Zhang, J., Nie, T., Pan, Y., Wu, D., et al. (2015). Adiponectin enhances cold-induced browning of subcutaneous adipose tissue via promoting m2 macrophage proliferation. Cell Metab. 22, 279-290. doi: 10.1016/j.cmet. 2015.06.004

Ikeda, K., Maretich, P., and Kajimura, S. (2018). The common and distinct features of brown and beige adipocytes. Trends Endocrinol. Metab. 29, 191-200. doi: 10.1016/j.tem.2018.01.001

Isakson, P., Hammarstedt, A., Gustafson, B., and Smith, U. (2009). Impaired preadipocyte differentiation in human abdominal obesity: role of Wnt, tumor necrosis factor-alpha, and inflammation. Diabetes 58, 1550-1557. doi: 10.2337/ $\mathrm{db} 08-1770$

Iwayama, T., Steele, C., Yao, L., Dozmorov, M. G., Karamichos, D., Wren, J. D., et al. (2015). PDGFR $\alpha$ signaling drives adipose tissue fibrosis by targeting progenitor cell plasticity. Genes Dev. 29, 110-119. doi: 10.1101/gad.260554.115

Jeffery, E., Wing, A., Holtrup, B., Sebo, Z., Kaplan, J. L., Saavedra-Peña, R., et al. (2016). The adipose tissue microenvironment regulates depot-specific adipogenesis in obesity. Cell Metab. 24, 142-150. doi: 10.1016/j.cmet.2016.05. 012

Jiang, Y., Berry, D. C., Jo, A., Tang, W., Arpke, R. W., Kyba, M., et al. (2017). A $\operatorname{PPAR} \gamma$ transcriptional cascade directs adipose progenitor cell-niche interaction and niche expansion. Nat. Commun. 8:15926. doi: 10.1038/ncomms15926

Jones, J. E. C., Rabhi, N., Orofino, J., Gamini, R., Perissi, V., Vernochet, C., et al. (2020). The Adipocyte acquires a fibroblast-like transcriptional signature in response to a high fat diet. Sci Rep. 10:2380. doi: 10.1038/s41598-020-59284-w

Kane, H., and Lynch, L. (2019). Innate immune control of adipose tissue homeostasis. Trends Immunol. 40, 857-872. doi: 10.1016/j.it.2019.07.006

Keophiphath, M., Achard, V., Henegar, C., Rouault, C., Clément, K., and Lacasa, D. (2009). Macrophage-secreted factors promote a profibrotic phenotype in human preadipocytes. Mol. Endocrinol. 23, 11-24. doi: 10.1210/me.2008-0183

Kershaw, E. E., and Flier, J. S. (2004). Adipose tissue as an endocrine organ. J. Clin. Endocrinol. Metab. 89, 2548-2556. doi: 10.1210/jc.2004-0395

Khan, T., Muise, E. S., Iyengar, P., Wang, Z. V., Chandalia, M., Abate, N., et al. (2009). Metabolic dysregulation and adipose tissue fibrosis: role of collagen VI. Mol. Cell Biol. 29, 1575-1591. doi: 10.1128/mcb.01300-08

Lacasa, D., Taleb, S., Keophiphath, M., Miranville, A., and Clement, K. (2007). Macrophage-secreted factors impair human adipogenesis: involvement of proinflammatory state in preadipocytes. Endocrinology 148, 868-877. doi: 10. 1210/en.2006-0687

Lagathu, C., Yvan-Charvet, L., Bastard, J. P., Maachi, M., Quignard-Boulangé, A., Capeau, J., et al. (2006). Long-term treatment with interleukin-1 $\beta$ induces insulin resistance in murine and human adipocytes. Diabetologia 49, 21622173. doi: $10.1007 / \mathrm{s} 00125-006-0335-\mathrm{z}$

Lee, M. W., Odegaard, J. I., Mukundan, L., Qiu, Y., Molofsky, A. B., Nussbaum, J. C., et al. (2015). Activated type 2 innate lymphoid cells regulate beige fat biogenesis. Cell 160, 74-87. doi: 10.1016/j.cell.2014.12.011

Lee, Y. H., Petkova, A. P., and Granneman, J. G. (2013). Identification of an adipogenic niche for adipose tissue remodeling and restoration. Cell Metab. 18, 355-367. doi: 10.1016/j.cmet.2013.08.003

Lee, Y. H., Petkova, A. P., Mottillo, E. P., and Granneman, J. G. (2012). In vivo identification of bipotential adipocyte progenitors recruited by $\beta 3$ adrenoceptor activation and high-fat feeding. Cell.Metab. 15, 480-491. doi: 10.1016/j.cmet.2012.03.009

Lin, J. Z., Rabhi, N., and Farmer, S. (2018). Myocardin-related transcription factor a promotes recruitment of ITGA5+ profibrotic progenitors during obesityinduced adipose tissue fibrosis. Cell Rep. 23, 1977-1987. doi: 10.1016/j.celrep. 2018.04.057

Lumeng, C. N., Bodzin, J. L., and Saltiel, A. R. (2007a). Obesity induces a phenotypic switch in adipose tissue macrophage polarization. J. Clin. Invest. 117, 175-184. doi: 10.1172/JCI29881

Lumeng, C. N., Deyoung, S. M., and Saltiel, A. R. (2007b). Macrophages block insulin action in adipocytes by altering expression of signaling and glucose transport proteins. Am. J. Physiol. Endocrinol. Metab. 292, 166-174. doi: 10. 1152/ajpendo.00284.2006
Macdougall, C. E., and Longhi, M. P. (2019). Adipose tissue dendritic cells in steady-state. Immunology 156, 228-234. doi: 10.1111/imm.13034

Macotela, Y., Emanuelli, B., Mori, M. A., Gesta, S., Schulz, T. J., Tseng, Y. H., et al. (2012). Intrinsic differences in adipocyte precursor cells from different white fat depots. Diabetes 61, 1691-1699. doi: 10.2337/db11-1753

Marcelin, G., Ferreira, A., Liu, Y., Atlan, M., Aron-Wisnewsky, J., Pelloux, V., et al. (2017). A PDGFR $\alpha$-mediated switch toward CD9high adipocyte progenitors controls obesity-induced adipose tissue fibrosis. Cell Metab. 25, 673-685. doi: 10.1016/j.cmet.2017.01.010

Marcelin, G., Silveira, A. L. M., Martins, L. B., Ferreira, A. V., and Clément, K. (2019). Deciphering the cellular interplays underlying obesityinduced adipose tissue fibrosis. J. Clin. Invest. 129, 4032-4040. doi: 10.1172/JCI129192

Meln, I., Wolff, G., Gajek, T., Koddebusch, J., Lerch, S., Harbrecht, L., et al. (2019). Dietary calories and lipids synergistically shape adipose tissue cellularity during postnatal growth. Mol. Metab. 24, 139-148. doi: 10.1016/j.molmet.2019.03.012

Merrick, D., Sakers, A., Irgebay, Z., Okada, C., Calvert, C., Morley, M. P., et al. (2019). Identification of a mesenchymal progenitor cell hierarchy in adipose tissue. Science 364:eaav2501. doi: 10.1126/science.aav2501

Michailidou, Z. (2019). Fundamental roles for hypoxia signalling in adipose tissue metabolism and inflammation in obesity. Curr. Opin. Physiol. 12, 39-43. doi: 10.1016/j.cophys.2019.09.005

Min, S. Y., Desai, A., Yang, Z., Sharma, A., DeSouza, T., Genga, R. M. J., et al. (2019). Diverse repertoire of human adipocyte subtypes develops from transcriptionally distinct mesenchymal progenitor cells. Proc. Natl. Acad. Sci. U.S.A. 116, 17970-17979. doi: 10.1073/pnas.1906512116

Molofsky, A. B., Nussbaum, J. C., Liang, H. E., Van Dyken, S. J., Cheng, L. E., Mohapatra, A., et al. (2013). Innate lymphoid type 2 cells sustain visceral adipose tissue eosinophils and alternatively activated macrophages. J. Exp. Med. 210, 535-549. doi: 10.1084/jem.20121964

Moysidou, M., Karaliota, S., Kodela, E., Salagianni, M., Koutmani, Y., Katsouda, A., et al. (2018). CD8+ T cells in beige adipogenesis and energy homeostasis. JCI Insight 3:e95456. doi: 10.1172/jci.insight.95456

Nawaz, A., Aminuddin, A., Kado, T., Takikawa, A., Yamamoto, S., Tsuneyama, K., et al. (2017). CD206+ M2-like macrophages regulate systemic glucose metabolism by inhibiting proliferation of adipocyte progenitors. Nat. Commun. 8:286. doi: 10.1038/s41467-017-00231-231

Nishimura, S., Manabe, I., Nagasaki, M., Hosoya, Y., Yamashita, H., Fujita, H., et al. (2007). Adipogenesis in obesity requires close interplay between differentiating adipocytes, stromal cells, and blood vessels. Diabetes 56, 1517-1526. doi: 10. 2337/db06- 1749

Obregon, M. J. (2014). Adipose tissues and thyroid hormones. Front. Physiol. 5:479. doi: 10.3389/fphys.2014.00479

Okla, M., Zaher, W., Alfayez, M., and Chung, S. (2018). Inhibitory effects of tolllike receptor 4 , NLRP3 inflammasome, and interleukin- $1 \beta$ on white adipocyte browning. Inflammation 41, 626-642. doi: 10.1016/j.physbeh.2017.03.040

Ouchi, N., Parker, J. L., Lugus, J. J., and Walsh, K. (2011). Adipokines in inflammation and metabolic disease. Nat. Rev. Immunol. 11, 85-97. doi: 10. 1038/nri2921

Palhinha, L., Liechocki, S., Hottz, E. D., Pereira, J. A. D. S., de Almeida, C. J., Moraes-Vieira, P. M. M., et al. (2019). Leptin induces proadipogenic and proinflammatory signaling in adipocytes. Front. Endocrinol. 10:841. doi: 10. 3389/fendo.2019.00841

Pamir, N., Liu, N. C., Irwin, A., Becker, L., Peng, Y., Ronsein, G. E., et al. (2015). Granulocyte/macrophage colony-stimulating factor-dependent dendritic cells restrain lean adipose tissue expansion. J. Biol. Chem. 290, 14656-14667. doi: 10.1074/jbc.M115.645820

Pazos, P., Lima, L., Tovar, S., González-Touceda, D., Diéguez, C., and García, M. C. (2015). Divergent responses to thermogenic stimuli in BAT and subcutaneous adipose tissue from interleukin 18 and interleukin 18 receptor 1-deficient mice. Sci Rep. 5, 17977. doi: 10.1038/srep17977

Peirce, V., Carobbio, S., and Vidal-Puig, A. (2014). The different shades of fat. Nature 510, 76-83. doi: 10.1038/nature13477

Permana, P. A., Nair, S., Lee, Y. H., Luczy-Bachman, G., Vozarova De Courten, B., and Tataranni, P. A. (2004). Subcutaneous abdominal preadipocyte differentiation in vitro inversely correlates with central obesity. Am. J. Physiol. Endocrinol. Metab. 286, E958-E962. doi: 10.1152/ajpendo.00544.2003

Qiu, Y., Nguyen, K. D., Odegaard, J. I., Cui, X., Tian, X., Locksley, R. M., et al. (2014). Eosinophils and type 2 cytokine signaling in macrophages orchestrate 
development of functional beige fat. Cell 157, 1292-1308. doi: 10.1016/j.cell. 2014.03.066

Raajendiran, A., Ooi, G., Bayliss, J., O’Brien, P. E., Schittenhelm, R. B., Clark, A. K., et al. (2019). Identification of metabolically distinct adipocyte progenitor cells in human adipose tissues. Cell Rep. 27, 1528.e7-1540.e7. doi: 10.1016/j.celrep. 2019.04.010

Rodeheffer, M. S., Birsoy, K., and Friedman, J. M. (2008). Identification of white adipocyte progenitor cells in vivo. Cell 135, 240-249. doi: 10.1016/j.cell.2008. 09.036

Rodríguez, A., Ezquerro, S., Méndez-Giménez, L., Becerril, S., and Frühbeck, G. (2015). Revisiting the adipocyte: a model for integration of cytokine signaling in the regulation of energy metabolism. Am. J. Physiol. Endocrinol. Metab. 309, E691-E714. doi: 10.1152/ajpendo.00297.2015

Rønningen, T., Shah, A., Reiner, A. H., Collas, P., and Moskaug, J. Ø (2015). Epigenetic priming of inflammatory response genes by high glucose in adipose progenitor cells. Biochem. Biophys. Res. Commun. 467, 979-986. doi: 10.1016/j. bbrc.2015.10.030

Rosen, E. D., and MacDougald, O. A. (2006). Adipocyte differentiation from the inside out. Nat. Rev. Mol. Cell Biol. 7, 885-896. doi: 10.1038/nrm2066

Rosen, E. D., and Spiegelman, B. M. (2014). What we talk about when we talk about fat. Cell 156, 20-44. doi: 10.1016/j.cell.2013.12.012

Rosenwald, M., Perdikari, A., Rülicke, T., and Wolfrum, C. (2013). Bi-directional interconversion of brite and white adipocytes. Nat. Cell Biol. 15, 659-667. doi: $10.1038 / \mathrm{ncb} 2740$

Rotter, V., Nagaev, I., and Smith, U. (2003). Interleukin-6 (IL-6) induces insulin resistance in 3T3-L1 adipocytes and is, like IL-8 and tumor necrosis factor-alpha, overexpressed in human fat cells from insulinresistant subjects. J. Biol. Chem. 278, 45777-45784. doi: 10.1074/jbc.M3019 77200

Sakamoto, T., Nitta, T., Maruno, K., Yeh, Y. S., Kuwata, H., Tomita, K., et al. (2016). Macrophage infiltration into obese adipose tissues suppresses the induction of UCP1 level in mice. Am. J. Physiol. Endocrinol. Metab. 310, E676-E687. doi: 10.1152/ajpendo.00028.2015

Schwalie, P. C., Dong, H., Zachara, M., Russeil, J., Alpern, D., Akchiche, N., et al. (2018). A stromal cell population that inhibits adipogenesis in mammalian fat depots. Nature 559, 103-108. doi: 10.1038/s41586-018-0226-8

Shao, M., Vishvanath, L., Busbuso, N. C., Hepler, C., Shan, B., Sharma, A. X., et al. (2018). De Novo adipocyte differentiation from Pdgfr $\beta+$ preadipocytes protects against pathologic visceral adipose expansion in obesity. Nat. Commun. 9:890. doi: 10.1038/s41467-018-03196-x

Shao, M., Wang, Q. A., Song, A., Vishvanath, L., Busbuso, N. C., Scherer, P. E., et al. (2019). Cellular origins of beige fat cells revisited. Diabetes 68, 1874-1885. doi: $10.2337 / \mathrm{db} 19-0308$

Shapouri-Moghaddam, A., Mohammadian, S., Vazini, H., Taghadosi, M., Esmaeili, S. A., Mardani, F., et al. (2018). Macrophage Plasticity, polarization, and function in health and disease. J. Cell Physiol. 233, 6425-6440. doi: 10.1002/ jcp. 26429

Spalding, K. L., Arner, E., Westermark, P. O., Bernard, S., Buchholz, B. A., Bergmann, O., et al. (2008). Dynamics of fat cell turnover in humans. Nature 453, 783-787. doi: 10.1038/nature06902

Sun, C., Berry, W. L., and Olson, L. E. (2017). PDGFR $\alpha$ controls the balance of stromal and adipogenic cells during adipose tissue organogenesis. Development 144, 83-94. doi: 10.1242/dev.135962

Sun, K., Park, J., Gupta, O. T., Holland, W. L., Auerbach, P., Zhang, N., et al. (2014). Endotrophin triggers adipose tissue fibrosis and metabolic dysfunction. Nat. Commun. 19:3485. doi: 10.1038/ncomms4485

Sun, K., Tordjman, J., Clément, K., and Scherer, P. E. (2013). Fibrosis and adipose tissue dysfunction. Cell Metab. 18, 470-477. doi: 10.1016/j.cmet.2013.06.016

Sun, K., Wernstedt Asterholm, I., Kusminski, C. M., Bueno, A. C., Wang, Z. V., Pollard, J. W., et al. (2012). Dichotomous effects of VEGF-A on adipose tissue dysfunction. Proc. Natl. Acad. Sci. U.S.A. 109, 5874-5879. doi: 10.1073/pnas. 1200447109

Tang, W., Zeve, D., Suh, J. M., Bosnakovski, D., Kyba, M., Hammer, R. E., et al. (2008). White fat progenitor cells reside in the adipose vasculature. Science 322, 583-586. doi: 10.1126/science.1156232
Tchkonia, T., Tchoukalova, Y. D., Giorgadze, N., Pirtskhalava, T., Karagiannides, I., Forse, R. A., et al. (2005). Abundance of two human preadipocyte subtypes with distinct capacities for replication, adipogenesis, and apoptosis varies among fat depots. Am. J. Physiol. Endocrinol. Metab. 288, E267-E277. doi: 10.1152/ ajpendo.00265.2004

Traktuev, D. O., Merfeld-Clauss, S., Li, J., Kolonin, M., Arap, W., Pasqualini, R., et al. (2008). A population of multipotent CD34-positive adipose stromal cells share pericyte and mesenchymal surface markers, reside in a periendothelial location, and stabilize endothelial networks. Circ Res. 102, 77-85. doi: 10.1161/ CIRCRESAHA.107.159475

Vishvanath, L., and Gupta, R. K. (2019). Contribution of adipogenesis to healthy adipose tissue expansion in obesity. J. Clin. Invest. 129, 4022-4031. doi: 10.1172/ JCI129191

Vishvanath, L., MacPherson, K. A., Hepler, C., Wang, Q. A., Shao, M., Spurgin, S. B., et al. (2016). Pdgfr $\beta+$ mural preadipocytes contribute to adipocyte hyperplasia induced by high-fat-diet feeding and prolonged cold exposure in adult mice. Cell Metab. 23, 350-359. doi: 10.1016/j.cmet.2015.10.018

Wang, W., Ishibashi, J., Trefely, S., Shao, M., Cowan, A. J., Sakers, A., et al. (2019). A PRDM16-driven metabolic signal from adipocytes regulates precursor cell fate. Cell Metab. 30, 174.e5-189.e5. doi: 10.1016/j.cmet.2019.05.005

Wang, H., Shen, L., Sun, X., Liu, F., Feng, W., Jiang, C., et al. (2019). Adipose group 1 innate lymphoid cells promote adipose tissue fibrosis and diabetes in obesity. Nat. Commun. 10:3254. doi: 10.1038/s41467-019-11270-1

Wang, W., and Seale, P. (2016). Control of brown and beige fat development. Nat. Rev. Mol. Cell Biol. 17, 691-702. doi: 10.1038/nrm.2016.96

Weiner, F. R., Shah, A., Smith, P. J., Rubin, C. S., and Zern, M. A. (1989). Regulation of collagen gene expression in 3T3-L1 cells. Effects of adipocyte differentiation and tumor necrosis factor alpha. Biochemistry 28, 4094-4099. doi: 10.1021/bi00435a070

Weinstock, A., Brown, E. J., Garabedian, M. L., Pena, S., Sharma, M., Lafaille, J., et al. (2019). Single-cell RNA sequencing of visceral adipose tissue leukocytes reveals that caloric restriction following obesity promotes the accumulation of a distinct macrophage population with features of phagocytic cells. Immunometabolism 1:e190008. doi: 10.20900/immunometab20190008

Weisberg, S. P., McCann, D., Desai, M., Rosenbaum, M., Leibel, R. L., and Ferrante, A. W. Jr. (2003). Obesity is associated with macrophage accumulation in adipose tissue. J. Clin. Invest. 112, 1796-1808. doi: 10.1172/JCI200319246. Introduction

Wu, D., Molofsky, A. B., Liang, H. E., Ricardo-Gonzalez, R. R., Jouihan, H. A., Bando, J. K., et al. (2011). Eosinophils sustain adipose alternatively activated macrophages associated with glucose homeostasis. Science 32, 243-247. doi: 10/1126/science. 1201475

Wu, J., Boström, P., Sparks, L. M., Ye, L., Choi, J. H., Giang, A. H., et al. (2012). Beige adipocytes are a distinct type of thermogenic fat cell in mouse and human. Cell 150, 366-376. doi: 10.1016/j.cell.2012.05.016

Wynn, T. A. (2008). Cellular and molecular mechanisms of fibrosis. J. Pathol. 16, 26-39. doi: $10.1002 /$ path.2277

Zhang, R., Gao, Y., Zhao, X., Gao, M., Wu, Y., Han, Y., et al. (2018). FSP1-positive fibroblasts are adipogenic niche and regulate adipose homeostasis. PLoS Biol. 16:e2001493. doi: 10.1371/journal.pbio.2001493

Zheng, C., Yang, Q., Cao, J., Xie, N., Liu, K., Shou, P., et al. (2016). Local proliferation initiates macrophage accumulation in adipose tissue during obesity. Cell Death Dis. 7:e2167. doi: 10.1038/cddis.2016.54

Conflict of Interest: The authors declare that the research was conducted in the absence of any commercial or financial relationships that could be construed as a potential conflict of interest.

Copyright (c) 2020 Pyrina, Chung, Michailidou, Koutsilieris, Chavakis and Chatzigeorgiou. This is an open-access article distributed under the terms of the Creative Commons Attribution License (CC BY). The use, distribution or reproduction in other forums is permitted, provided the original author(s) and the copyright owner(s) are credited and that the original publication in this journal is cited, in accordance with accepted academic practice. No use, distribution or reproduction is permitted which does not comply with these terms. 